\title{
Quantificação de resíduos de madeira provenientes de empresas moveleiras de pequeno porte e alternativas de aproveitamento
}

\author{
Roberta Samara Barros Nunes ${ }^{1 \star}$, Juan Carlos Valdés Serra ${ }^{1}$
}

${ }^{1}$ Programa de Pós-Graduação em Agroenergia (PPGA), Universidade Federal do Tocantins, Palmas, TO, Brasil.

\begin{abstract}
RESUMO O estudo teve como objetivo estimar a taxa de aproveitamento da matéria-prima e a quantidade de resíduos de madeira provenientes de movelarias em Palmas - TO visando as possíveis alternativas para o aproveitamento ou descarte correto. O trabalho foi realizado a partir de visitas técnicas em pequenas empresas moveleiras com a finalidade de analisar e descrever o processo produtivo de cada uma, identificando cada etapa de produção, onde o resíduo é gerado e qual a máquina é a fonte geradora. Além dessa primeira etapa, observou-se os tipos de resíduos produzidos e a quantificação desses resíduos. Outro fator analisado foi a matéria-prima florestal (madeira serrada e painéis), objetivando o controle de entrada, taxa de aproveitamento e o descarte, na forma de resíduo. As movelarias descartam pequenas quantidades de matéria-prima, entretanto, busca-se incentivar e informar os proprietários sobre a importância do aproveitamento adequado de cada resíduo, ou seja, na geração de novos produtos, com valor agregado ou na economia da matéria-prima. As alternativas de aproveitamento citadas foram: produção de pequenos objetos de madeira, geração de calor, painéis aglomerados, forragem em lavouras e hortas, artesanatos.
\end{abstract}

Keywords: matéria-prima, processo produtivo, reaproveitamento, gestão ambiental.

\section{Quantification of wood wastes from small furniture companies and alternatives for their use}

\begin{abstract}
The objective of this study was to estimate the rate of utilization of the raw material and the amount of wood residues coming from the Palmas - TO warehouses, with a view to the possible alternatives for proper recovery or disposal. The work was carried out from technical visits in small furniture companies with the purpose of analyzing and describing the productive process of each one, identifying each stage of production, where the residue is generated, and which machine is the generating source. In addition to this first stage, the types of residues produced, and the quantification of these residues were observed. Another factor analyzed was the forest raw material (sawn wood and panels), aiming at the entrance control, utilization rate and disposal in the form of waste. The furniture stores discard small quantities of raw material; however, we seek to encourage and inform the owners about the importance of the proper use of each waste, that is, in the generation of new products, with added value or in the economy of the raw material. The alternatives of utilization cited were production of small objects of wood, heat generation, agglomerated panels, fodder in crops and vegetable gardens, handicrafts
\end{abstract}

Keywords: raw material, production process, reuse, environmental management.

\section{Introdução}

O setor moveleiro em Tocantins vem destacando-se devido ao crescimento da construção civil. Em Palmas, capital do estado, pequenos empresários aproveitaram para investir na fabricação de móveis planejados. O crescimento da atividade implicou na geração de emprego e renda e desenvolvimento econômico na região. Entretanto, com o aumento na produção, aumenta-se significativamente a geração de resíduo, considerados problemas para a gestão ambiental nas empresas. A geração dos resíduos de madeira nas movelarias pode ser observada em três etapas, no processamento primário da madeira, no processo produtivo 
dos móveis (corte e acabamento), e, no final do ciclo de vida do móvel (HILLIG et al., 2009).

Brito e Cunha (2009), afirmam que devido às consequências da exploração inadequada no passado foram ocasionados irreversíveis danos ao meio ambiente, gerando preocupações que levaram a buscar medidas para mitigar estes problemas, assim, as empresas estão buscando melhorarias no seu desempenho ambiental. Grandes empresas processadoras de madeira já aderiram de alguma forma o gerenciamento ambiental e o aproveitamento integrado dos seus subprodutos, porém, as empresas de pequeno e médio porte, ainda apresentam dificuldades na hora do descarte adequado do resíduo que é gerado.

Com isso, busca-se diferentes formas para o aproveitamento dos resíduos de madeira dentro da própria empresa geradora, visando alternativas de baixo custo, e que possam gerar lucros, a exemplo da produção de subprodutos ambientalmente corretos e, que de alguma forma, possam ser comercializáveis (FORNRI et al., 2015). Esses resíduos podem ser destinados para produção de material combustível (briquetes e pellets), na agricultura (compostagem e cama de aviário), na geração de energia elétrica (termoelétricas), na indústria de painéis reconstituídos e para produção de pequenos objetos (brinquedos e adornos) (ABREU, 2009). A relação harmoniosa entre empresas e o meio ambiente maximiza a produtividade dos recursos utilizados, acarretando em benefícios diretos, fundamentados na economia de matéria-prima e insumos, resultantes, principalmente, do processamento mais eficiente ou da sua substituição, reutilização e reciclagem, na redução dos custos das atividades envolvidas no manuseio, transporte e descarte dos resíduos (COELHO et al, 2011).

Diante do exposto, buscar alternativas de aproveitamento dos resíduos é necessário, para isso é preciso que se conheça quais os tipos de resíduos são gerados, as fontes geradoras e dimensionamento da quantidade, logo, o presente trabalho tem como objetivo, estimar a taxa de aproveitamento da matéria-prima e a quantidade de resíduos de madeira provenientes de movelarias em Palmas visando as possíveis alternativas para o aproveitamento ou descarte correto.

\section{Material e Métodos}

\section{Coleta de dados, matéria-prima e resíduo}

Para levantamento de dados sobre as movelarias em Palmas buscou-se informações no Sindicato das Indústrias de Madeira e Mobiliário do Estado do Tocantins (SIMAM-TO), a partir das informações levantadas nota-se que a capital é caracterizada pela predominância de empresas de pequeno porte, onde exigem pequena quantidade de mão-de-obra e uma pequena produtividade. Foram selecionadas 15 empresas situadas no setor industrial, para seleção determinou-se critérios, como, o porte (pequeno porte); matéria-prima consumida (madeira) e produto (móveis).

Foram realizadas visitas técnicas nas 15 movelarias, uma vez na semana em um período de um mês, com o intuito de observar o processo produtivo de cada empresa, destacando a matéria-prima predominante na região e o volume utilizado mensalmente. Em relação aos resíduos, foram analisados quanto à sua origem (operação geradora) e quanto ao fator gerador (características da matéria-prima, equipamento ou ferramenta que contribui para a geração). Observou-se também, o tipo de resíduo gerado, segundo Dutra et al (2005) estes são agrupados como: pó de serra (originados da operação de serras); cepilho (originados nas operações de aplainamento) e destopos, com maiores dimensões, compostos por costaneiras, aparas, refilos, resíduos de topo de tora, restos de lâmina. Para quantificação da matéria-prima foi mensuradas as dimensões das chapas de madeira consumidas mensalmente (Figura 3). E a quantificação dos resíduos foi realizada a partir do volume dos tambores armazenados (Figura 4), com as medições realizadas mensalmente. 


\section{Questão ambiental}

Foram coletados dados sobre tecnologias que prezem pelo meio ambiente, como, a utilização de coletor de pó, exaustor, ciclone, filtro de manga, entre outros, empresas que trabalham com o processamento de madeira necessitam desses tipos de tecnologias para retirar a poeira da atmosfera e evitar problemas de poluição do ar. Por fim, os resíduos de madeira receberam alternativas de aproveitamento, deixando de ser um problema ambiental, passando a ser subprodutos das próprias empresas geradoras ou, até mesmo, receber destinação fora delas, a exemplo, o descarte ambiental adequado.

\section{Resultados e Discussão}

\section{Processo produtivo}

Constitui em dois modelos, os estofados e os móveis retilíneos. A linha de estofados é composta basicamente por sófas, poltronas, puffs e sófas-cama. Já os móveis retilíneos são as cozinhas moduladas, móveis para escritório, estantes, guarda-roupas, camas, cômodos, entre outros.

\section{Produção de móveis estofados}

O primeiro passo para fabricação de um estofado é a preparação dos painéis conforme o tamanho e o modelo, a etapa é conhecida como pré-corte, realizada na marcenaria. Em seguida, ocorre o dimensionamento da peça. Dependendo do modelo do estofado, é necessário realizar o corte em curva, para estabelecer seu contorno. Produz o braço, o assento e o encosto. É necessário fazer também perfurações nas peças já que elas precisam de orifícios. O segundo passo é tapeçaria, etapa na qual ocorre a preparação da espuma e dos tecidos, incluindo o processo de costura e acabamento. O terceiro passo consiste na proteção interna dos estofados (tecido TNT ou ráfia). A Figura 1 apresenta os moldes do assento e do braço do estofado.
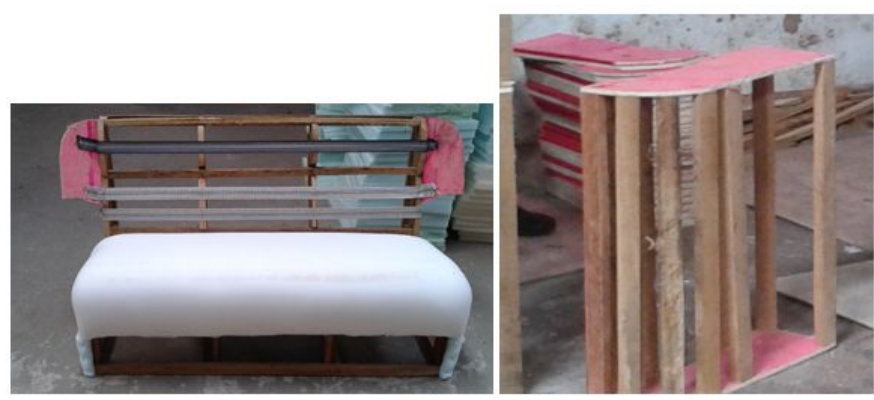

Figura 1. Moldes do assento e do braço do estofado. Figure 1. Upholstered seat and arm molds.

Os maquinários que foram observados na produção de estofados são: compressor, lixadeira, respigadeira, tupia, plaina desengrossadeira, plaina desempenadeira, serra esquadrejadeira, serra circular, serra fita, furadeira, laminadora de espuma, forrageira, máquina de costura e grampeador.

A Tabela 1 demonstra os equipamentos que produzem resíduos de madeira, a etapa em que são gerados e os tipos de resíduos produzidos.

De acordo com dados da Tabela 1, são três os maquinários utilizados pelas empresas produtoras de estofados que geram três tipos de resíduos de madeira, ou seja, os três tipos de serras são responsáveis por gerar, destopos, pó de serra e cepilho, enquanto dois dos maquinários (plainas) produzem cepilho e pó de serra e, apenas a furadeira produz pó de serra.

Tabela 1. Equipamentos utilizados na produção de estofados, etapa da produção e os resíduos gerados.

Table 1. Equipment used in the production of upholstery, production stage and waste generated.

\begin{tabular}{|c|c|c|}
\hline Equipamento & $\begin{array}{l}\text { Etapa de } \\
\text { produção }\end{array}$ & Resíduo gerado \\
\hline $\begin{array}{c}\text { Serra } \\
\text { esquadrejadeira }\end{array}$ & Pré-corte & $\begin{array}{c}\text { Destopo, pó de } \\
\text { serra, cepilho }\end{array}$ \\
\hline Serra circular & Serrafiamento & $\begin{array}{c}\text { Destopo, pó de } \\
\text { serra, cepilho }\end{array}$ \\
\hline Serra fita & Corte curvo & $\begin{array}{c}\text { Destopo, pó de } \\
\text { serra, cepilho }\end{array}$ \\
\hline $\begin{array}{c}\text { Plaina } \\
\text { desempenadeira }\end{array}$ & $\begin{array}{c}\text { Desempenar a } \\
\text { peça }\end{array}$ & $\begin{array}{c}\text { Cepilho e pó de } \\
\text { serra }\end{array}$ \\
\hline $\begin{array}{c}\text { Plaina } \\
\text { desengrossadeira }\end{array}$ & $\begin{array}{l}\text { Retirar } \\
\text { excesso da } \\
\text { peça }\end{array}$ & $\begin{array}{c}\text { Cepilho e pó de } \\
\text { serra }\end{array}$ \\
\hline Furadeira & $\begin{array}{c}\text { Perfurar a } \\
\text { peça }\end{array}$ & Pó de serra \\
\hline
\end{tabular}




\section{Produção de móveis retilíneos}

De acordo com as visitas técnicas, observou-se que a produção de móveis retilíneos envolve várias etapas e diversos equipamentos. Inicialmente, a matéria-prima vai para o setor de corte, onde a esquadrejadeira dimensiona as peças que irão compor o móvel. Posteriormente, os itens são enviados para um setor de corte secundário. Após as duas etapas iniciais, são realizadas as operações de colagem de fita de borda, ou seja, o acabamento lateral e as furações que servem de suporte para as dobradiças. Após, as peças são agrupadas e encaminhadas para o setor de montagem. Quando necessário, algumas peças são pré-montadas e preparadas para pintura. Em seguida, as peças são enviadas para o acabamento, onde recebem acessórios (gavetas, fechaduras, etc.). Depois faz a limpeza do móvel, finalizando a produção. Finalmente, o móvel pronto é embalado e segue para o setor de armazenagem. A Figura 2 ilustra parte da produção de um móvel retilíneo (A) e a exposição do móvel pronto (B).

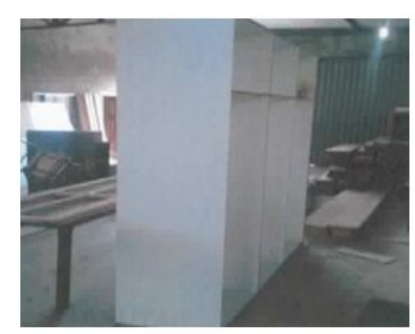

(A)

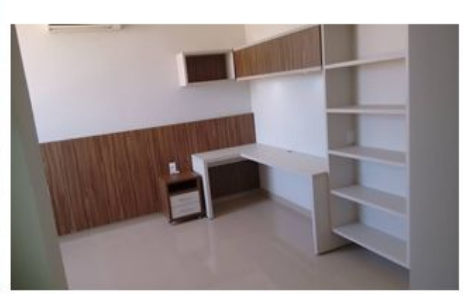

(B)
Figura 2. Parte da produção de um móvel retilíneo (A) e a exposição do móvel pronto (B).

Figure 2. Part of the production of a rectilinear furniture (A) and the exhibition of the ready furniture (B).

Os maquinários utilizados na produção de móveis retilíneos são: coladeira de borda, seccionadora, plaina desempenadeira, furadeira, tupia, serra esquadrejadeira, lixadeira, rolo de pintura e prensa. Os equipamentos que geram resíduos de madeira foram listados na Tabela 2, juntamente com as etapas da produção e os tipos de resíduos gerados.
Tabela 2. Equipamentos utilizados na produção de móveis retilíneos, etapa da produção e os resíduos gerados.

Table 2. Equipment used in the production of rectilinear furniture, production stage and waste generated.

\begin{tabular}{|c|c|c|}
\hline Equipamento & Etapa & Resíduo gerado \\
\hline $\begin{array}{c}\text { Serra } \\
\text { esquadrejadeira }\end{array}$ & $\begin{array}{c}\text { Corte de } \\
\text { madeira (reta) }\end{array}$ & $\begin{array}{l}\text { Destopo, pó de serra, } \\
\text { cepilho }\end{array}$ \\
\hline Seccionadora & $\begin{array}{c}\text { Corte de } \\
\text { madeira (reta) }\end{array}$ & $\begin{array}{l}\text { Destopo, pó de serra, } \\
\text { cepilho }\end{array}$ \\
\hline Tupia & $\begin{array}{c}\text { Corte de } \\
\text { madeira } \\
\text { (modulado) }\end{array}$ & Cepilho, pó de serra \\
\hline $\begin{array}{c}\text { Plaina } \\
\text { desempenadeira }\end{array}$ & $\begin{array}{c}\text { Desempenar a } \\
\text { peça }\end{array}$ & Cepilho, pó de serra \\
\hline $\begin{array}{c}\text { Furadeira } \\
\text { manual }\end{array}$ & $\begin{array}{l}\text { Furação de } \\
\text { peça }\end{array}$ & Pó de serra \\
\hline Lixadeira & $\begin{array}{l}\text { Lixamento de } \\
\text { peça }\end{array}$ & Pó de serra \\
\hline
\end{tabular}

De acordo com a Tabela 2, todos os equipamentos utilizados na fabricação de móveis retilíneos produzem pó de serra. É importante ressaltar que a diferença entre a serra esquadrejadeira e a seccionadora está na tecnologia que apresentam. A seccionadora possui alta precisão de corte, fato que dispensa o trabalho adicional de máquinas para fresar ou plainar, por meio da plaina ou tupia, que seriam outros equipamentos geradores de resíduos de madeira, além de apresentar grande praticidade de operação. No entanto, a serra esquadrejadeira está mais presente nas movelarias devido ao seu baixo preço em relação a seccionadora, fator que influencia na hora da escolha por parte dos empresários.

\section{Matéria-prima utilizada nas movelarias}

A matéria-prima utilizada nas movelarias é proveniente de madeira serrada das espécies de Pinus ssp. e Eucalipto ssp. e painéis de madeira (MDF, aglomerados e compesado). Como madeira serrada, algumas empresas utilizam também as espécies de Hymenolobium petraeum Ducke e Ocotea ssp. A Tabela 3 apresenta o volume dos dois tipos de matériaprima (painéis e madeira serrada) utilizados mensalmente por cada empresa. 
Tabela 3. Quantidade mensal de painéis de madeira e madeira serrada.

Table 3. Monthly amount of wood panels and lumber.

\begin{tabular}{|c|c|c|c|}
\hline \multicolumn{4}{|c|}{ Quantidade de matéria-prima mensal } \\
\hline Empresas & $\begin{array}{l}\text { Painéis de madeira }\left(\mathrm{m}^{3}\right) \text { (MDF, } \\
\text { aglomerado e compensado) }\end{array}$ & Madeira serrada $\left(\mathrm{m}^{3}\right)$ & Total $\left(\mathrm{m}^{3}\right)$ \\
\hline E1 & 2,9952 & 0 & 2,9952 \\
\hline E2 & 3,1824 & - & 3,1824 \\
\hline E3 & 1,3478 & 1,254 & 2,6018 \\
\hline $\mathrm{E} 4$ & 2,9952 & 1,672 & 4,6672 \\
\hline E5 & 1,4976 & 0 & 1,4976 \\
\hline E6 & 1,7224 & 0 & 1,7224 \\
\hline E7 & 2,9952 & 1,045 & 4,0402 \\
\hline E8 & 1,8729 & - & 1,8729 \\
\hline E9 & 2,9952 & 0 & 2,9952 \\
\hline E10 & 3,2198 & 0 & 3,2198 \\
\hline E11 & 3,2947 & - & 3,2947 \\
\hline E12 & 2,6582 & 0 & 2,6582 \\
\hline E13 & 2,4710 & 1,045 & 3,5160 \\
\hline E14 & 2,6208 & 0 & 2,6208 \\
\hline E15 & NUU & - & - \\
\hline Total & 35,868 & 5,016 & 40,884 \\
\hline
\end{tabular}

A média do consumo mensal de matéria-prima é de aproximadamente 2,92 $\mathrm{m}^{3}$. Nota-se que a maioria das movelarias trabalha apenas com painéis de madeira, devido a operabilidade mais rápida e serem mais fáceis de manuseio. A Figura 3 ilustra dois tipos de matéria-prima (painéis e madeira serrada), utilizadas nas empresas moveleiras.
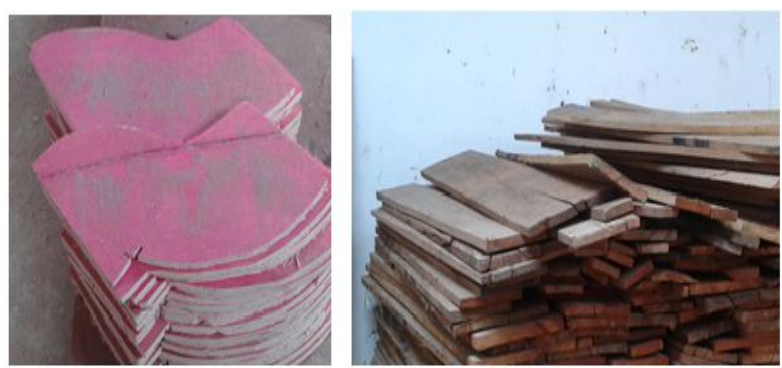

Figura 3. Matéria-prima (painéis e madeira serrada). Figure 3. Raw material (panels and lumber).

\section{Resíduos de madeira gerados nas movelarias}

Durante as visitas técnicas constatou-se que não existe controle quantitativo do volume de resíduos de madeira gerados. Esses resíduos compostos de pó de serra, cepilhos e destopos, não possuem segregação adequada, uma vez que são armazenados juntos em tambores metálicos para serem encaminhados para o aterro sanitário do município ou ficar estocados dentro da empresa. Para descobrir o volume mensal de resíduos foi necessário quantificar o total de tambores utilizados para armazenagem e o seu volume. $\mathrm{Na}$ Figura 4 pode-se observar como é realizado o armazenamento dos resíduos.
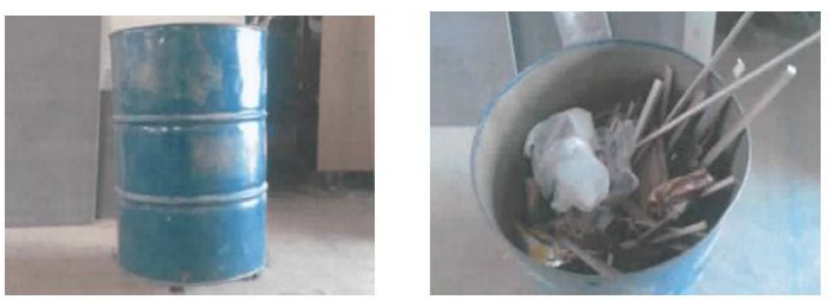

Figura 4. Tambores de armazenamento dos resíduos (200 ml) Figure 4. Wood waste storage drums $(200 \mathrm{ml})$.

Conforme analisado na Figura 4, percebe-se que os resíduos de madeira são armazenados juntamente com outros tipos de resíduos (tecido, plásticos, entre outros), isso é notável em boa parte das movelarias. Em busca de valores mais próximos dos reais, fez-se um levantamento para identificar a quantidade desses outros resíduos e excluí-los do volume total dos tambores. A quantidade de tambores utilizados mensalmente, a capacidade e o volume total de 
resíduo de madeira, assim como, os valores de aproveitamento da matéria-prima e o reaproveitamento são demonstrados na Tabela 4.

Não foi possível estimar a porcentagem do aproveitamento da matéria-prima utilizada pela empresa 15 (E15). Nota-se que 20\% das empresas reaproveitam seus

A partir da obtenção destes valores foi possível calcular a porcentagem de aproveitamento da matéria-prima. O maior aproveitamento foi realizado pela empresa 1 (E1), 87,98\%, e o mais baixo pela empresa 4 (E4), 61,01\%. Hilling et al. (2004), identificaram na Serra Gaúcha um aproveitamento de, aproximadamente, $94 \%$ dos painéis de madeira, ocasionado pelo manejo adequado, utilização de tecnologia no processamento primário e à capacitação e treinamento da mão de obra. A média mensal do volume de resíduos das empresas estudadas é de aproximadamente 1,05 $\mathrm{m}^{3}$. Sabendo que, $1 \mathrm{~m}^{3}$ equivale a aproximadamente $190 \mathrm{~kg}$ de mistura de resíduos de MDF e madeira natural (HILLING et al., 2004), pode-se afirmar que as movelarias estudadas geram em um mês aproximadamente $1.117 \mathrm{~kg}$ de resíduos de madeira. Os resíduos devem ser estudados e receber uma destinação resíduos dentro do próprio processo produtivo de móveis para produção de peças menores. E apenas uma empresa doa seus resíduos para uma oficina onde é utilizado como combustíveis para caldeiras de recapagem. O restante das empresas, 73,34\%, destinam seus resíduos de madeira para o aterro sanitário do município.

adequada, para evitar problemas ambientais, tais como: poluição do ar devido à queima; utilização de extensas áreas para descarte; assoreamento e poluição de rios; entre outros.

\section{Visão ambiental das empresas}

Os equipamentos que foram encontrados nas empresas que visam contribuir com o meio ambiente são, coletor de pó (coleta material no interior da fábrica), ciclone (coleta material por meio de força centrífuga), filtro de manga (coleta pó e partículas). Outro fato encontrado, é que nenhuma empresa possui um profissional responsável pela questão ambiental e não possuem programas que incentivem e habilitem o reaproveitamento e a reciclagem. como matériaprima (ABREU, 2009).

Tabela 4. Volume de resíduos de madeira gerados pelas empresas selecionadas.

Table 4. Volume of wood waste generated by selected companies.

\begin{tabular}{cccccc} 
Empresa & $\begin{array}{c}\mathbf{N}^{\circ} \text { de } \\
\text { tambores }\end{array}$ & $\begin{array}{c}\text { Capacidade dos } \\
\text { tambores }\left(\mathbf{m}^{\mathbf{3}}\right)\end{array}$ & $\begin{array}{c}\text { Volume total de resíduos } \\
\text { de madeira }\left(\mathbf{m}^{\mathbf{3}}\right)\end{array}$ & $\begin{array}{c}\text { Aproveitamento da } \\
\text { matéria-prima (\%) }\end{array}$ & $\begin{array}{c}\text { Reaproveitamento de } \\
\text { resíduos na produção }\end{array}$ \\
\hline E1 & 2 & 0,2 & 0,36 & 87,98 & Não \\
E2 & 3 & 0,2 & 0,42 & 86,80 & Não \\
E3 & 3 & 0,2 & 0,42 & 83,85 & Não \\
E4 & 4 & 0,5 & 1,86 & 61,01 & Não \\
E5 & 2 & 0,2 & 0,36 & 75,09 & Não \\
E6 & 2 & 0,2 & 0,36 & 79,09 & Não \\
E7 & 3 & 0,5 & 1,32 & 67,32 & Não \\
E8 & 3 & 0,2 & 0,42 & 77,57 & Não \\
E9 & 4 & 0,2 & 0,62 & 79,30 & Não \\
E10 & 3 & 0,2 & 0,42 & 86,95 & Sim \\
E11 & 2 & 0,5 & 0,82 & 75,11 & Não \\
E12 & 3 & 0,25 & 0,57 & 78,55 & Não \\
E13 & 4 & 0,2 & 0,62 & 82,36 & Não \\
E14 & 3 & 0,2 & 0,42 & 83,97 & Sim \\
E15 & 2 & 0,2 & 6,82 & - & Sim \\
\hline
\end{tabular}


Verificou-se também que os proprietários e a equipe de trabalho não estão cientes das responsabilidades quanto à disposição final do material gerado. De acordo com a Resolução do CONAMA № 237, de 19 de dezembro de 1997, a própria atividade poluidora deverá promover o tratamento e disposição final de seus resíduos, o empreendimento não deverá colocar dificuldades para realizar determinadas ações. As movelarias deverão identificar empreendimentos que utilizem, ou possam vir a utilizar, resíduos de madeira em seus processos produtivos

\section{Proposta de aproveitamento dos resíduos de madeira}

Para aproveitar adequadamente os resíduos de madeira é necessária uma segregação diferente para os tipos de resíduos (destopos, cepilhos e pó de serra) e para os tipos de matériaprima (painéis e chapas e madeira serrada), tornando-se relevante a realização de cursos de capacitação para os proprietários e funcionários, a fim de, muni-los de conhecimento, a ponto de solucionar problemas referentes ao o armazenamento do resíduo, classificação, quantificação, reutilização e transformação em subprodutos de valor agregado dentro ou fora da empresa.

A segregação diferenciada é de extrema importância, pois, facilita a reutilização no processo e a destinação final. Também, permite a separação de resíduos com propriedades peculiares, como é o caso de alguns painéis de madeira, por ser compostos por materiais laminados e resinas aglutinantes que quando catalisados em altas temperaturas podem transmitir toxicidade, não são viáveis para certos usos (ABREU, 2009). A exemplo da produção de briquetes, por liberar emissões tóxicas, ou para produção de alguns pequenos objetos de madeira, como, uma colher de pau, por ser submetida em altas temperaturas pode causar intoxicações ou alergias.

Entretanto, materiais com essas propriedades podem ser utilizados para produção de novos painéis, onde as movelarias poderão fornecer esse tipo de resíduo como matéria-prima para produção de um produto com baixo custo, podendo ser absorvido pelo próprio mercado moveleiro ou construção civil.

Sem a presença de materiais contaminantes, o resíduo pode ser considerado como banal e não inerte, pois é biodegradável classificado pela NBR 10004 (ABNT, 1987) como classe II. Entre as diversas formas de aproveitamento, podemos citar: a fabricação de pequenos objetos de madeira, medida simples, podendo ser confeccionados dentro das movelarias, aproveitando o equipamento e a mão de obra existente. Neste caso aproveita-se até os resíduos de menores dimensões. Alguns objetos que podem ser confeccionados são: artigos domésticos de caráter utilitário, de caráter decorativo, de uso pessoal, brinquedos, complementos de outros produtos, entre outros. Outro exemplo de utilização é a confecção de briquetes, o resíduo poderá ser vendido ou doado para empresas que os produza, utilizando-os para aquecer caldeiras, fornos, entre outros. Método realizado por uma das movelarias estudadas, a ideia poderia ser compartilhada com os demais empresários.

$\mathrm{Ou}$, podem ser doados para artesões para fabricação de peças e utensílios pequenos. Em alguns casos são utilizadas as lascas de madeira e pó como forragem em lavouras e hortas consistindo em melhorar as condições biológicas do solo e dificultar a germinação de ervas daninhas ou outras vegetações rasteiras. Paisagistas utilizam pequenos pedaços de madeira como cobertura morta em jardins por agregar um aspecto bonito no ambiente.

As técnicas de aproveitamento citadas agregarão valor monetário ao produto final e possibilitará um novo material para concorrer com outros existentes no mercado, além da contribuição ao meio ambiente. Outro fator que poderia contribuir com a redução de desperdício da matéria-prima é a aquisição de máquinas e equipamentos modernos, que aumentaria o aproveitamento e, consequentemente, gerariam 
menos resíduos. Porém, a baixa produtividade das empresas e os altos custos do maquinário inviabilizam a sua aquisição.

\section{Conclusões}

As movelarias apresentaram um taxa de aproveitamento da matéria-prima de aproximadamente $73,27 \%$, valor considerado baixo quando comparado com valores da literatura, podendo ser explicado pelo fato das pequenas empresas ter começado o seu processo de industrialização de produção de móveis por meio de agrupamentos familiares, passando técnicas de pais para filhos, não buscando uma melhoria no processamento por meio de máquinas e equipamentos modernos;

A produção de resíduos de madeira equivale a $1.117 \mathrm{~kg}$ por mês. O valor não apresenta, em curto prazo, problemas para o aterro sanitário do município, mas, é necessário o incentivo a aplicação de medidas mitigadoras para melhorar a qualidade ambiental da empresa aumentando a reutilização dos resíduos e prolongar a vida útil do aterro;

Os níveis de aproveitamento e reutilização dentro das movelarias não foram significativos, os funcionários não são encorajados a realizar uma produção com pouco desperdício;

A mistura dos diferentes tipos de resíduos dificulta a venda ou o aproveitamento para outras empresas;

As alternativas de aproveitamento propostas, tais como: fabricação de novos painéis de madeira, briquetes e pequenos objetos, e, utilização como matéria morta em jardins ou forragem em lavoura, poderão ser acatadas pelo setor moveleiro, são medidas simples e eficazes, que garantem valorizar o resíduo e contribuir com questões ambientais;

A falta de incentivo dos pequenos empresários está relacionada com os baixos números apresentados, sendo necessário capacitações e treinamentos para se obter um sistema de gerenciamento eficaz dentro das empresas.

\section{Referências}

ABREU, LB.; MENDES, L.M.; SILVA, J.R.M. Aproveitamento de resíduos de painéis de madeira gerados pela indústria moveleira na produção de pequenos objetos. Revista Árvore, v. 33, n. 1, p. 171-177, 2009.

ASSOCIAÇÃO BRASILEIRA DE NORMS TECNICAS. NBR 10004: Classificação dos resíduos sólidos. Rio de janeiro, 2004.

BRITO, L.S.; CUNHA, M.E.T. Reaproveitamento de Resíduos da Indústria Moveleira. Cient. Exatas Tecnol, v. 8, n. 1, p. 23-26, 2009.

COELHO, H.M.G.; LANGE, L.C.; JESUS, L.F.L.; SARTORI, M. R. Proposta de um Índice de destinação de Resíduos Sólidos Industriais. Engenharia Sanitária Ambiental, v.16, n.3, p. 307-316, 2011.

CONSELHO NACIONAL DO MEIO AMBIENTE. Resolução no 237 de 19 de dezembro de 1988. Diário Oficial da União, 1997.

NASCIMENTO, S.M; DUTRA, R.I.J.P.; NUMAZAWA, S. Resíduos de Indústria Madeireira: Caracterização, Consequências sobre o Meio Ambiente e Opções de Uso. Holos Environment [s.l.], v. 6, n. 1, p. 083-534, 2006.

HILLIG, E.; SCHNEIDER, V.E.; PAVONI, E.T. Geração de resíduos de madeira e derivados da indústria moveleira em função das variáveis de produção. Produção, v. 19, n. 2, p. 292-303, 2009.

FORNARI, F. DE ASSIS. L. \& AHRENS, R. B. Resíduos sólidos da indústria moveleira de Arapongas - PR e sua mitigação. Espacios, v. 36, n. 8, p.13, 2015.

HILLIG, E.; SCHNEIDER, V. E.; PAVONI, E. T. Diagnóstico da geração de resíduos e dos sistemas de gestão ambiental das empresas do polo moveleiro da serra Gaúcha. In: PÓLO moveleiro da serra Gaúcha: geração de resíduos e perspectivas para sistemas de gerenciamento ambiental. Educs, p. 165, 2004.

LOPES, C.S.D. Desenho de pequenos objetos de madeira com resíduo da indústria de processamento mecânico da madeira. InterfacEHS, v. 4, n. 3, 2009.

MENDES. R.F.; GUIMARÃES JÚNIOR, J.B.; SANTOS, R.C.; SILVA CÉSAR, A.A. Efeito da associação de bagaço de cana, do tipo e do teor de adesivo na produção de painéis aglomerados. Ciência Florestal, v. 22, n. 1, p. 161-170. 2012. 